\title{
TENSIONES EN LA GESTIÓN DE LAS CARAVANAS MIGRANTES POR GUADALAJARA
}

\author{
TENSIONS IN THE MANAGEMENT OF MIGRANT \\ CARAVANS THROUGH GUADALAJARA
}

\author{
Manuela Camus Bergareche* \\ Heriberto Vega Villaseñor ${ }^{\star *}$ \\ Iliana Martínez Hernández Mejía ${ }^{\star * *}$
}

Resumen: En este artículo trataremos de explorar las múltiples tensiones que se producen en las operaciones para atender el paso de las Caravanas de 2018 y 2019 por la metrópolis de Guadalajara. Su paso expuso las capacidades de los gobiernos, de los medios, de su sociedad civil y religiosa organizada y de la sociedad en general, para asumir la llegada de tantas personas diferentes: extranjeros, pobres y desahuciados, entre otros. En este recuento nos interesa analizar las diferentes acciones y reacciones de algunos de los actores. Los gobiernos municipal y estatal -tanto con el exgobernador Aristóteles Sandoval (Partido Revolucionario Institucional), como con el actual, Enrique Alfaro (Movimiento Ciudadano)- se muestran ambiguos con acciones simultáneas de humanitarismo y criminalización, de visibilización e invisibilización

* Departamento de Estudios Sociourbanos, Universidad de Guadalajara. Líneas de investigación: Desplazamiento Forzado, Sufrimiento Social, Estudios de Migración. email: manuelacamus@gmail.com.

** Departamento de Ciencias Sociales y Disciplinas Filosófico, Metodológico e Instrumentales, Centro Universitario de Tonalá, Universidad de Guadalajara. Líneas de investigación: Acción Humanitaria, Estudios de Migración, Estudios de Religión. email: betovegamx@gmail. com.

*** Centro Interdisciplinario para la Formación y Vinculación Social, ITESO. Líneas de investigación: Estudios de Migración, Comunidades Transnacionales. email: ilianamtz@gmail. com.

Fecha de recepción: 01/09/2019, fecha de aceptación: 31/10/2019, fecha de publicación: $31 / 01 / 2020$.

(oc) EY-NC-ND Páginas 62-91 
Camus Bergareche

Vega Villaseñor

Martínez Hernández
Tensiones en la gestión de las caravanas migrantes...

del fenómeno. Finalmente, se reflexiona sobre los comportamientos "desconcertantes" y los eventos de agencia de los integrantes de las Caravanas.

Palabras clave: Caravanas migrantes, insostenibilidad de la vida, acción política, eventos de agencia migrante, migración centroamericana.

Abstract: In this chapter we will explore the multiple tensions that occur in the operations of the Caravans of 2018 and 2019 through the metropolis of Guadalajara. The movement exposed the capacities of governments, the media, of organized civil and religious society and of the local society to assume the arrival of so many different people: foreigners, poor, and/or evicted. We are interested in analyzing the different actions and reactions of some of the key actors. The municipal and state governments - both with the former governor Aristotle Sandoval (Partido Revolucionario Institucional, PRI), as with the current governor Enrique Alfaro (Citizen Movement) - are ambiguous with simultaneous actions of humanitarianism and criminalization, of visibility and invisibility of the phenomenon. Finally, we reflect on the "disconcerting" behaviors and agency events of the Caravans members.

Keywords: Migrant caravans, unsustainability of life, political action, events of migrant agency, Central American migration.

\section{Introducción ${ }^{1}$}

La convocatoria por redes sociales para conformar una salida colectiva hacia la frontera de México y Estados Unidos, llegó a reunir a varios miles de hondureños en San Pedro Sula, Honduras, en octubre de 2018. A ellos se les fueron sumando otros contingentes según avanzaba la Caravana por Guatemala y México. Esta estrategia de autoprotección frente al peligroso cruce por el territorio mexicano recibió cierta coordinación de parte de algunas organizaciones de activistas una vez entrada a México, fue atendida por múltiples instancias oficiales - con su ambigüedad entre la obstaculización y la aquiescencia- y no oficiales, generando inicialmente una amplia simpatía

\footnotetext{
${ }^{1}$ Este ha sido un trabajo de reflexión colectiva, el grupo contaba además con Sofía de la Peña (ITESO) y los estudiantes del ITESO Josué Hildelgardo Gómez Guzmán y Gisela Guadalupe Centeno López. Todos los participantes han estado involucrados en la recepción de las Caravanas desde diferentes instancias.
} 
de la población y una cobertura extensa por parte de los medios. Parecía tener una estrategia y un destino definido: Tijuana.

La composición heterogénea de estas movilizaciones confirma que hace tiempo que se ha roto con el masculinizado patrón de los migrantes “irregulares" en México. Fue la novedosa presencia de mujeres y niños como parte de segmentos familiares, grupos organizados de personas transgénero y LGBTTTIQ+, y adultos de 35 y más años, entre muchos hombres jóvenes, lo que generó necesidades diferentes. Posteriormente esta modalidad masiva se fue desagregando por su difícil gestión operativa interna y externa. A su interior se desgajarán grupos que no corren con la misma suerte en los aventones, por ejemplo, o que requerirán otro ritmo de avance, o generarán liderazgos propios y/o se harán autónomos; también por los contingentes que se suman, y por las acciones institucionales con sus apoyos u omisiones, por ejemplo, con el transporte. De tal manera que quizás es más factible hablar de oleadas de migrantes, donde se pueden encontrar diferentes modalidades: los gruesos de población, identificados como Caravanas, y sus fragmentos, como pequeñas asociaciones transitorias.

A pesar de las vinculaciones que se le conjeturaban a esta primera convocatoria, respecto a las confabulaciones políticas relacionadas con las elecciones intermedias en Estados Unidos, la involucración (desestabilizadora para el presidente Donald Trump) del magnate Georges Soros, o la intervención de narcotraficantes hondureños, en el sentido común la Caravana fue entendida como un movimiento de explosión social ante la insostenibilidad de la vida en los países centroamericanos que buscaba proteger a los migrantes de los abusos del crimen organizado en el territorio mexicano ${ }^{2}$.

La expresión de desplazamiento masivo que fueron las Caravanas en 2018 y en 2019 desbordó las políticas y prácticas migratorias de México y de Estados Unidos, sus integrantes reformularon las reglas del juego en torno al papel de los gobiernos, de la sociedad civil, de las instancias religiosas y de la "ayuda humanitaria". Esta "marabunta" humana desestabilizó el panorama político a nivel continental e irrumpió como la expresión y la acción de

${ }^{2}$ Con insostenibilidad de la vida queremos abarcar las extremas precarizaciones del mundo contemporáneo, sumadas a procesos históricos de despojo y sufrimiento social que arrojan a los sujetos a situaciones límite donde la elección posible se restringe a la huida, el exilio o el desplazamiento (Camus, 2019). Con este término queremos trascender el limitado e injusto entendido de la llamada "migración económica" y fortalecer el hecho del masivo desplazamiento forzado internacional. 
los desheredados, mostrando el nivel de urgencia de su fuga, exponiendo las deficiencias, omisiones y ambigüedades de las políticas migratorias de México y Estados Unidos, el fracaso de las iniciativas, planes y proyectos de desarrollo que se han diseñado y financiado, así como la perversa indolencia de los gobiernos centroamericanos ante las condiciones de expulsión de sus "ciudadanos".

Detrás de todo esto se encuentra la poderosa sombra de Estados Unidos, omnisciente y omnipresente, actor principal en esta situación crítica de desplazamiento como responsable histórico y actual del mismo. Su reacción, a través de implacables medidas extorsivas a México y Centroamérica para el control migratorio, ha provocado un inconmensurable sufrimiento social de los expulsados de Centroamérica y otros lugares del mundo.

En este artículo trataremos de exponer las múltiples tensiones que se produjeron en las operaciones para atender el paso de estas Caravanas por Jalisco y por la metrópolis de Guadalajara, mismas que moldean la acción política y social de los agentes involucrados. En una primera sección haremos un repaso de los hechos, donde mostraremos a los actores en su diversidad, dándole su lugar a quienes son parte de los sectores civiles y religiosos, que tienden a ser ignorados en estos recuentos. En la segunda parte reflexionamos sobre una expresión social tan trascendental como son las Caravanas y el desplazamiento por insostenibilidad de la vida: haremos un balance sobre la gestión de las mismas en su paso por Jalisco, abordaremos el comportamiento "desconcertante" de las personas migrantes centroamericanas y, finalmente, problematizamos sobre la agencia migrante, que entendemos como eventos de agencia.

\section{Las caravanas por Jalisco y Guadalajara}

El paso de diferentes caravanas por Guadalajara ha expuesto las capacidades de sus gobiernos, de los medios, de su sociedad civil y religiosa organizada, y de la sociedad tapatía para asumir la llegada de tantas personas diferentes: extranjeros, pobres y desahuciados, entre otros. En este recuento nos interesa analizar las diferentes acciones y reacciones de algunos de los actores. Queremos mostrar el cóctel explosivo que se genera por las diferentes tensiones, posiciones e intereses frente a una sempiterna crisis humanitaria que envuelve a miles de desplazados. Los gobiernos municipal y estatal -tanto con el 
exgobernador Aristóteles Sandoval (PRI), como con el actual, Enrique Alfaro (Movimiento Ciudadano)- se muestran ambiguos con acciones simultáneas de humanitarismo y criminalización, de visibilización e invisibilización del fenómeno. Para ello han recurrido a diferentes maniobras, la que termina por legitimarse ha sido recibirlas en la carretera de entrada a la ciudad, para posteriormente depositar a sus integrantes en las casetas de la autopista en la salida hacia Nayarit, y no en sus límites con este estado, algo que, como veremos, la sociedad civil ha empujado.

Consideraremos también a los dirigentes semiclandestinos de las caravanas -pragmáticos en lo operativo y, a veces, políticamente iluminados- y la tenacidad de los sujetos migrantes, a su vez movidos por cierta capacidad de organización pero, sobre todo, desde el imperativo de la necesidad. Dentro de este escenario tirante, complejo y desbordado, la "sociedad civil" de Guadalajara (organizaciones civiles y religiosas) se ha mostrado sensible y capaz, pero limitada por su composición compleja y sus posiciones diferenciadas respecto a la colaboración con el Estado. Y tenemos una sociedad dividida donde la oposición visceral contra el pobre, el migrante y el extranjero empieza a mostrarse más públicamente con la complacencia oficial y de los medios.

El recurso de movilizarse en Caravanas no es nuevo. Están la Antorcha Guadalupana de reivindicación de los derechos de los indocumentados mexicanos en Estados Unidos y de testimonio de fe por las familias divididas por la frontera desde 2001, las Caravanas de Madres Centroamericanas, que iniciaron recorridos por las rutas migrantes en busca de los hijos desaparecidos desde 2004, o los Viacrucis migrantes desde 2010.

En Guadalajara hay cuatro albergues activos. Uno es el de FM4 Paso Libre, que funciona como tal desde $2015^{3}$. Otros dos son obra de los hermanos Scalabrinis, uno de ellos es Aldea Arcoiris y el otro es la Casa del Migrante de Guadalajara. Mientras que el cuarto, El Refugio Casa del Migrante y del Refugiado en Tlaquepaque, a las orillas de la ciudad, es una iniciativa de la pastoral social de la Parroquia del Cerro del 4. Dirigida por el Padre Alberto Ruiz, recibe personas migrantes desde el 2012. En 2017 se amplió para recibir a refugiados y a inmigrantes con la intención de asentarse en México. Es este proyecto el que recibió, en 2017 y 2018, a los viacrucis migrantes durante la semana santa y diciembre, acompañados por Pueblo Sin Fronteras ${ }^{4}$.

${ }^{3}$ La organización existe desde 2007, el albergue que actualmente operan, desde 2015.

${ }^{4}$ Organización transnacional de defensa de los derechos de los migrantes, fundada en 1987. 
Camus Bergareche

Vega Villaseñor

Martínez Hernández
Tensiones en la gestión de las caravanas migrantes...

\section{Las caravanas de octubre de 2018}

Durante el 2018 se dieron desplazamientos masivos de personas provenientes de diversos países del norte de Centroamérica en dos momentos. El primer grupo, de alrededor de 1,500 personas en su ingreso a México, recorrió el país en los meses de marzo a mayo en dirección a la ciudad de Tijuana, vía la ruta occidente-pacífico. El colectivo se fue reduciendo, por lo que al realizar una parada en El Refugio Casa del Migrante de Guadalajara, ya se conformaba por sólo 650 personas.

El segundo momento, entre los meses de octubre y diciembre, suponía un salto en términos del número de personas y la forma de movilizarse al constituirse por múltiples grupos desplazándose de manera simultánea, en lo que se denominó Caravana de migrantes. El primer contingente, que ingresó a México el 19 de octubre, fue el más visible y el que aglutinó un mayor número de personas; le siguieron, por lo menos, cuatro grupos más de diversos tamaños, de entre 250 y 2,000 personas cada uno (COLEF, 2019) 5 . La Comisión Nacional de Derechos Humanos estima que en total se activaron alrededor de 10,000 personas entre octubre y noviembre de 2018 (CNDH, 2018).

En la Zona Metropolitana de Guadalajara (Imagen 1), los tres contingentes más numerosos cruzaron en diversos momentos y formas la ciudad. El más numeroso, y el único al que se le dio albergue por parte de las autoridades, fue de 6,000 integrantes y llegó entre el 11 y 12 de noviembre (CEDHJ, 2018: 19). Posteriormente, las Caravanas se fragmentaron y se reunieron en grupos más pequeños, lo cual les permitió a varios de ellos arribar al albergue de El Refugio. Se estima que, en total, 2,000 personas se movilizaron por la ruta occidente en esta segunda etapa (CEDHJ, 2018: 28).

Tanto en el contexto estatal como en el municipal, las autoridades se encontraban en un periodo de transición. Unos días antes, el 30 de septiembre, tomó posesión el nuevo gobierno en el municipio de Guadalajara; así como los reelegidos en Zapopan y Tlaquepaque. En el Estado de Jalisco estaban en la

Es miembro de la Red Nacional de Organizaciones de Jornaleros, pero, sobre todo, Pueblo Sin Fronteras es conocido por organizar las caravanas o viacrucis migrantes, y por haber sido el apoyo logístico en las Caravanas de octubre de 2018 y enero de 2019. Su líder más conocido es Irineo Mujica, quien, junto con otros compañeros, ha sido perseguido, detenido y criminalizado por estas acciones.

5 Observatorio COLEF del 5 oct de 2018 al 30 ene 2019. https://observatoriocolef.org/ infograficos/cronologia-de-la-caravana-centroamericana/ 
etapa de entrega al nuevo gobierno, el cambio de poder del PRI a Movimiento Ciudadano se realizaría hasta el 6 de diciembre. Estos relevos tienen efectos en las formas y el interés en el atender a las Caravanas.

Imagen 1. Área Metropolitana de Guadalajara, Jalisco

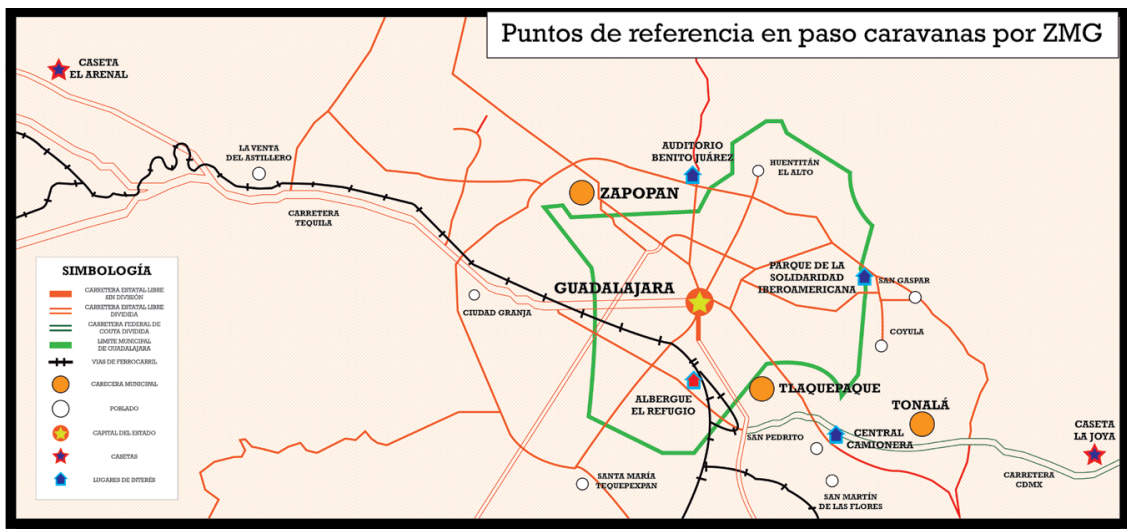

Autor: Enricco Sapien

\section{Preparativos para la recepción y atención de las Caravanas}

Los integrantes del área de migración de la Comisión Estatal de Derechos Humanos de Jalisco - CEDHJ- convocaron a instituciones públicas y a la sociedad civil a una reunión el 25 de octubre para definir una estrategia de atención a las Caravanas que pasarían por Jalisco, rumbo a Tijuana. Se acordó que sería el Instituto Jalisciense para Migrantes (IJAMI) el responsable de coordinar las acciones (CEDHJ, 2018, 17) . El 9 de noviembre, el secretario de gobierno Roberto López Lara confirma que se albergará a las personas migrantes en el Auditorio Benito Juárez, ubicado en una colonia dentro de la ciudad; y manifiesta que se mantendrá abierto "el tiempo que sea necesario" (Cerna, 2018). En un inicio pareció que habría espacio para la colaboración entre instancias oficiales y parte de la sociedad civil, ya que fueron convocados a algunas reuniones y consultados en aspectos operativos.

\footnotetext{
${ }^{6} \mathrm{La}$ CEDHJ tiene un grupo de trabajo especializado en la agenda de derechos de personas migrantes y refugiados dentro de la Dirección de quejas, orientación y seguimiento. Este grupo ha tenido una presencia muy activa en el monitoreo y acompańamiento de las caravanas y en los cuestionamientos a las instituciones de gobierno.
} 
Camus Bergareche Vega Villaseñor Martínez Hernández
Tensiones en la gestión de las caravanas migrantes...

El punto de recepción sería la caseta de La Joya (ubicada en la entrada sur-oriente de la ciudad, en la autopista que viene de Ciudad de México; ver Imagen 2) y se despliega un operativo donde están presentes las diversas policías, autoridades municipales, servicios de salud, la CEDHJ y la $\mathrm{CNDH}$, entre otros, para recoger a las personas que arriban y trasladarlas al Auditorio.

El Auditorio es un recinto equipado para recibir a grandes números de personas. Se contó con baños y regaderas suficientes, un área de comedor (operada por los comedores móviles del DIF), así como una ropería. En la explanada principal se encontraban servicios móviles de salud por parte de Cruz Roja, Protección Civil, Secretaría de Salud del estado y la Universidad de Guadalajara. La CNDH y la CEDHJ asesoraron y recibieron quejas; ACNUR orientaba sobre los trámites para refugiados; FM4 Paso Libre brindaba información y coordinaba a los voluntarios que llegaban al lugar. Se contaba con internet gratuito y en las áreas de descanso se instalaron pantallas de televisión con micrófonos y bocinas para dar avisos y buscar personas, así como también para el entretenimiento. Algunas dependencias de gobierno y ciudadanos voluntarios llegaron para ofrecer servicios de cortes de pelo, actividades recreativas para menores y servicios religiosos.

El Auditorio Benito Juárez comenzó a operar el sábado 10 de noviembre y para el domingo 11 de noviembre llega el grueso de la gente. Ese día el gobernador del Estado, Aristóteles Sandoval, da un mensaje de bienvenida a las personas migrantes (Cerna, 2018).

\section{Las tensiones y el fin de la ejemplaridad}

Hay una importante presencia de seguridad policial, sobre todo en las afueras del recinto, pero también al interior del mismo. Los recelos iniciales que manifestaban muchos caravaneros por sentirse en una prisión, dado el exceso de control y seguridad, derivan en tensiones.

$\mathrm{Al}$ interior del recinto surgen algunas discusiones entre personas migrantes donde la policía tiene que mediar, cuando llegan algunos donativos, como casas de campańa, todos quieren acceder a ellos primero. El personal que reparte no tiene experiencia trabajando con personas migrantes y se generan dificultades. Además, surgen algunos altercados a las afueras del Auditorio que se sobredimensionan con los chismes. Conforme va llegando la noche, se van 
restringiendo la salida y la entrada, hasta que se prohíbe la salida de personas migrantes del recinto, lo cual molesta a algunos caravaneros.

\section{La ruptura y el caos}

El lunes 12 de noviembre se da una reunión de las autoridades del estado de Jalisco con los representantes de la Caravana, donde había varios miembros de Pueblo Sin Fronteras. Se decide retirar el apoyo oficial y se les avisa que se movilizará a las personas en autobuses a las 6:30 de la mańana del día siguiente. El gobierno estatal argumenta en un primer momento que no se tienen suficientes recursos para atender a todas las personas, más adelante dice que se consumieron drogas y alcohol al interior del recinto y que es arriesgado recibir a las Caravanas.

Otro punto de quiebre fue el lugar donde los dejarían los autobuses. En un principio el compromiso era llevarlos hasta Ixtlán del Río, Nayarit, donde los recibiría el gobierno de este estado. Sin embargo, al momento de trasladarlos en camiones, en la madrugada del martes 13 de noviembre -a las 5.30 am, antes de lo acordado-, los bajaron en la caseta de El Arenal, Jalisco, a $85 \mathrm{kms}$. de Ixtlán. Las personas se dieron cuenta que no era el punto convenido y

Imagen 2. Mapa del Estado de Jalisco

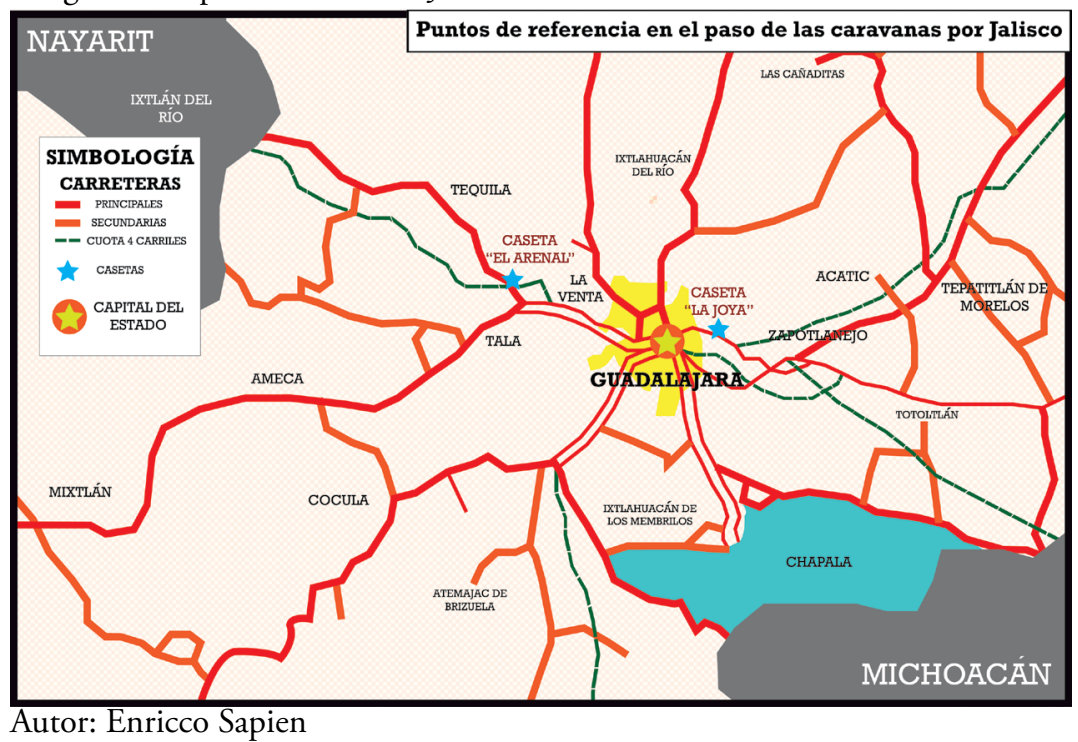


Camus Bergareche

Vega Villaseñor

Martínez Hernández
Tensiones en la gestión de las caravanas migrantes...

decidieron no descender para presionar a que los llevaran a Ixtlán. De acuerdo al informe de la CEDHJ, esto se realizó con amenazas por parte de la policía (2018).

Mientras, en el Auditorio, alrededor de las 9 de la mañana, muchas de las personas permanecían formadas de manera tranquila esperando el transporte. Otras estaban dormidas y otras más hacían la fila para desayunar. La mayoría no está enterada de lo que está sucediendo en la Caseta. Unos pocos se enteran por el megáfono de uno de los líderes, se molestan y toman la decisión de seguir el recorrido caminando. El resto de las personas se pasa la voz o simplemente siguen a los demás hacia El Arenal.

Es en este caos que el gobierno del estado determina el cierre del albergue, a las 14.30 del martes 13 , y advierte que no volverá a habilitar ni este ni otro recinto para dar cobijo y asistencia humanitaria a las personas migrantes.

\section{La sociedad civil ante la crisis de asistencia: un plan alternativo}

La Caravana saca un comunicado (Pueblo Sin Fronteras, 2018), alrededor de las 7 de la mańana, que circula a nivel local y nacional, donde denuncia el incumplimiento del gobierno de Jalisco. Esto genera una gran preocupación por parte de los medios de comunicación, sociedad civil y las Comisiones de Derechos Humanos. En este contexto, el FM4 publica un extrañamiento donde pide al gobierno aclarar la decisión (FM4 Paso Libre, 2018).

En El Arenal continúa el desajuste, algunos, en vez de esperar al resto de las personas desalojadas para movilizarse todos juntos, empiezan a moverse por su cuenta. Serán unas 1000 las personas, en su mayoría familias, que no pudieron irse en aventones.

A lo largo de la tarde, miembros de diversas iglesias, de la sociedad civil, de la CEDHJ, de la CNDH, de algunas universidades, ciudadanos solidarios e incluso de algunas dependencias de gobierno, se movilizan hacia la caseta de El Arenal para llevar víveres y ver en qué condición se encuentran las personas migrantes. Mientras, los que se han quedado deciden en asamblea pernoctar en las inmediaciones de la caseta ${ }^{7}$.

Son estas mismas organizaciones de la sociedad civil y de la iglesia las que gestionan, a sugerencia de la $\mathrm{CNDH}$, la movilización de las personas estancadas en El Arenal a través de 22 autobuses que salen hacia Ixtlán en

\footnotetext{
${ }^{7}$ Las asambleas se conformaban por alrededor de unas 25 personas integrantes de la Caravana que representaban al resto del grupo. Aunque en esta ocasión participa un grupo más numeroso.
} 
la madrugada del día 14. A partir de esta experiencia y ante el cambio de la postura de gobierno, este colectivo decide un plan alternativo de asistencia humanitaria para las Caravanas que están en camino: conseguir autobuses que transporten a las personas desde el ingreso de la ciudad, hasta llegar a Ixtlán. Las personas migrantes no pueden quedarse en la ciudad porque las organizaciones que atienden a migrantes no tienen capacidad para recibir a tantas personas; y si continuaban el viaje a pie, se expondrían al peligro que supone el crimen organizado en un Jalisco que es parte del corredor del narcotráfico. Finalmente, el gobierno de Nayarit también dispone autobuses para cruzar por su estado, por lo que se va generando un corredor vía autobús.

\section{La nueva estrategia del gobierno}

El jueves 15 de noviembre, el gobierno del estado de Jalisco dispone establecer nueve puntos de atención humanitaria sobre la ruta que atravesarían las personas migrantes. Al mismo tiempo la sociedad civil concreta la estrategia de los autobuses y se coordina la movilización de los grupos con gente de Pueblos Sin Fronteras. También, por encima de todo, personas migrantes siguen llegando a los albergues. El gobierno del estado presiona para que no se les acoja, pero el Padre Alberto de El Refugio continúa recibiendo a quienes llegan en pequeños grupos ${ }^{8}$. Las organizaciones logran dar la asistencia con los recursos que tienen y el apoyo solidario de muchas personas, por ejemplo: El Refugio recibió alrededor de 600 personas entre el 16 y 19 de noviembre (CEDHJ, 2018, 27). Muchos de ellos saldrían en autobuses hacia Ixtlán gracias a las gestiones de diversas instancias religiosas católicas.

Los puntos de atención del gobierno del estado no funcionaron como tales, la mayoría de los esfuerzos de todas las partes se concentraron en la caseta de La Joya, lugar que había designado la sociedad civil para que las personas que llegaran de aventón abordaran los autobuses. Hay presencia de Protección Civil, la Fiscalía, policías federales, estatales, municipales y de movilidad, de la CNDH y la CEDHJ, del DIF estatal, de ambulancias y paramédicos, quienes junto con personas o grupos de la sociedad civil y religiosa organizan

8 "El Pbro. Alberto Ruíz Pérez, director de El Refugio, recibió una advertencia por parte de personal que dijo pertenecer a la fiscalía, en donde amenazaron con detener los autobuses y a las personas que vinieran en ellos, ya que tenía información de que venían personas integrantes de una pandilla identificada como "maras"; no obstante, la mayor parte de las personas eran mujeres, niñas y niños” (CEDHJ, 2018: 27). 
el traslado de los migrantes. Destaca la coordinación por el Padre de la Rosa de Cáritas en diálogo con las autoridades presentes y con Pueblo Sin Fronteras.

Se calcula que fueron alrededor de 700 personas las que se movilizaron de esta forma. La acción del gobierno se puede calificar como irresponsable, ya que no brindaron la atención y protección humanitaria a todas las personas, las expusieron a condiciones inhóspitas y de inseguridad y delegaron en la sociedad civil una tarea que les corresponde?

\section{Las caravanas de enero de 2019}

Las Caravanas de enero se producen en un contexto con cambios significativos. En México, el 1 de diciembre inicia el gobierno de López Obrador, cuya propuesta de la Cuarta Transformación es un cambio radical respecto a las políticas neoliberales. Su énfasis está en una mayor redistribución de los recursos a través de políticas sociales. También en términos de política migratoria muestra un cambio de actitud. Aquí el discurso, acompanado del nombramiento de Tonatiuh Guillén, un respetado académico como comisionado del Instituto Nacional de Migración, asegura una política migratoria basada en la regularización de la migración, el ingreso ordenado y el tránsito seguro siguiendo el compromiso firmado por México en el Pacto Mundial de Marrakech sobre las Migraciones en diciembre de $2018^{10}$. Estas tres características, una migración segura, ordenada y regular, serán el mantra que repetirán los funcionarios del gobierno. Hay que añadir el ofrecimiento de trabajo a los centroamericanos en los megaproyectos del Canal interoceánico del istmo de Tehuantepec y del Tren Maya, y la promesa de incidir en los países centroamericanos expulsores de población a través de un plan de desarrollo

\footnotetext{
${ }^{9}$ En el "Informe Éxodo Centroamericano" quedará constancia del desalojo con uso de violencia por parte de la policía del estado de las personas migrantes en autobuses en la caseta del Arenal que puso en riesgo el derecho a la vida y a la integridad física (CEDHJ, 2018: 32); del cierre del auditorio Benito Juárez, que obligó a más de 1,500 personas a desplazarse caminando; de cómo las personas quedaron varadas en la caseta y el estado fue omiso en brindar alimentación, techo y servicios de salud adecuados (CEDHJ, 2018: 33); y, finalmente, de cómo se dieron transgresiones directas del derecho a la vida; a la integridad y seguridad personal; a la salud; al libre tránsito; al trato digno (CEDHJ, 2018: 33-34).

${ }^{10}$ Este pacto no es vinculante, Estados Unidos y otros países de la Organización de las Naciones Unidas no lo firman. Incluye compromisos concretos como medidas contra la trata y el tráfico de personas, evitar la separación de las familias, usar la detención de migrantes sólo como última opción o reconocer el derecho de los migrantes irregulares a recibir salud y educación en sus países de destino.
} 
para la región con diseño de la CEPAL, algo que presentará sin mucho éxito a Estados Unidos y a países europeos para su financiamiento. El gobierno no calibró lo que estas actitudes y acciones iban a provocar.

También hay cambios en los gobiernos estatales. En Jalisco entra Movimiento Ciudadano y el proyecto de la "Refundación" ciudadana, con Enrique Alfaro como gobernador. En este caso su apuesta es la modernización administrativa y supone una serie de reformas institucionales, entre ellas de las instancias de labor social. La Caravana coincide con una administración en el inicio de su mandato y en un proceso de cambios organizativos fuertes. Como veremos, este gobierno de Jalisco, como el anterior, evade la problemática de los migrantes en tránsito que le ofrece pocos créditos políticos de cara a la población.

\section{5 de enero 2019: "Buscamos refugio, en Honduras nos matan"}

Ante la necesidad y ante la percepción de que la Caravana de octubre habría resultado exitosa, se produce un nuevo llamado a conformar una Caravana en San Pedro Sula el 15 de enero, e inicia su recorrido con 1000 sujetos. A esta salida le siguen otras Caravanas y contingentes ${ }^{11}$. Aparecerán, de forma más contundente, inmigrantes de nuevas nacionalidades que poco a poco se van haciendo más numerosos y protagónicos: cubanos, haitianos, brasileños, de diferentes países de África... Los gobiernos centroamericanos endurecen sus posiciones, en Honduras tratan de retener a sus ciudadanos que no tienen papeles, también detendrán a un presunto organizador.

México, condescendiente desde el inicio, señala a través de Tonatiuh Guillén su empeño en la lógica del registro y les ofrece una visa humanitaria y $\mathrm{CURP}^{12}$ para el libre tránsito y para poder emplearse. En la frontera los reciben agentes del INM con información y equipos médicos. Los gobernadores de Chiapas, Oaxaca, Veracruz y Ciudad de México muestran su disposición a facilitarles apoyo y su paso con transporte, algo que cumplen. Para el 22 de enero hay ya 7,800 solicitantes del paso libre a México.

${ }^{11}$ El 16 de enero salen 200 personas de El Salvador; el 20 del mismo mes serán 2,000 de Honduras; incluso el 25 de marzo, cuando las reglas de juego han cambiado ya, sale una Caravana de 1,500 de Tapachula. Y el 30 de marzo lo hace una insólita con 600 cubanos y 200 centroamericanos.

${ }^{12}$ La Clave Única de Registro de Población se requiere en México para acceder a cualquier tipo de servicio o trámite, como lo es el sistema de salud, educación, trabajo, entre otros. 
Camus Bergareche

Vega Villaseñor

Martínez Hernández
Tensiones en la gestión de las

caravanas migrantes...

\section{Cambio de tuerca}

A partir de esta fecha hay un giro en la actitud del gobierno que se va haciendo explícita con el tiempo. Comienza con el aviso de que las tarjetas concedidas son una medida excepcional. Estados Unidos está presionando y el 25 de enero decide unilateralmente que los solicitantes de asilo en su país que hayan entrado por la frontera sur, tendrán que esperar en México, algo que este país acepta por "humanitarismo". Así se iniciará unilateralmente la externalización de su frontera: los migrantes deberán esperar en México la resolución de sus trámites de asilo en una estrategia de delegar y acentuar el problema de la asistencia. México lo acepta tácitamente y ello explica el giro de las medidas tomadas por el gobierno a partir de ese momento.

Las voces de las autoridades fronterizas del norte exigen al gobierno mexicano que se haga cargo de estos expulsados. $\mathrm{Y}$ es que los nuevos contingentes ya no se dirigen únicamente a Baja California, amplían sus caminos hacia otras ciudades de la frontera norte: Ciudad Juárez, Piedras Negras, Ciudad Acuña, que empiezan a recibir a estos colectivos. Se añade que muchos miembros de las primeras caravanas también se extienden por las ciudades de la frontera norte y por el país, mientras se intensifican los procesos de refugio ${ }^{13}$. El arribo de tanta población a la ciudad de Tijuana empezó a despertar el gusano de la xenofobia y se voltea la solidaridad recibida y mediatizada de la oleada anterior.

El parteaguas definitivo se produce cuando, a principios de febrero, acompañantes activistas de las Caravanas son aprehendidos y, poco después, unos policías golpean a dos mujeres activistas en la Ciudad de México: es la criminalización de la ayuda humanitaria. En menos de un mes algo se ha roto. Después de entregarse 13,270 pases (también en Ciudad de México y en Coahuila), no se van a tramitar más tarjetas. El paso libre ha sido breve.

De ahí se propagan los rumores de una Caravana madre que viene con 30,000 almas desde Colombia y, con ello, la idea de la llegada sin control de criminales y la necesaria persecución a la trata de personas. Todo ello exacerba, como en Estados Unidos, un imaginario de oleadas invasoras que despiertan miedos y recelos en una población mexicana que no entiende por qué los recursos se dirigen a no mexicanos. Esto facilita las nuevas medidas que se toman ahora de abandono del apoyo a los migrantes por las autoridades $y$

\footnotetext{
${ }^{13}$ México recibió a principios de los ochenta, por la guerra interna de Guatemala, a más de 40,000 refugiados.
} 
de clara obstaculización a los migrantes en tránsito con detenciones y deportaciones masivas por las fuerzas de seguridad y el INM en diferentes estados. Por el sur sigue fluyendo la población hacia la frontera norte, con sus albergues colapsados y con migrantes varados.

Lo que vemos se puede interpretar como parte del dispositivo expropiatorio que promueve el Estado, donde la criminalización conversión de los sujetos en criminales penalizables, en este caso de los desplazados- es la antesala a la represión directa, pues legitima el ejercicio de la fuerza pública (Composto y Navarro, 2014: 60). Así, mediante la desinformación, la manipulación informativa y la sobreexcitación emocional del lector generan un estado de opinión en el que los migrantes centroamericanos se perciben como amenazas para la sociedad.

\section{El arribo y paso por Guadalajara}

Por Jalisco pasarán dos grandes secciones de la Caravana que optaron por seguir esta vía de Occidente hacia Mexicali. Ambas van a llegar cuando el gobierno federal ha entrado en la fase paranoica de control y presión sobre los flujos migrantes. Es a mediados de febrero que, ante la inminente llegada de un gran contingente migrante, se tiene una reunión interinstitucional convocada por la coordinación de la recién creada Secretaría de Igualdad Sustantiva ${ }^{14}$. En ella están presentes la sociedad civil e instancias religiosas, que habían sido activas y críticas en la Caravana de octubre. Son los dos albergues en la ciudad: FM4 y El Refugio Casa del Migrante y Refugiado, la orden de los Scalabrinianos, Cáritas..., e instancias oficiales diversas: DIF, Igualdad Sustantiva, las Policías, INM, CEDHJ. La preocupación es cómo se va a atender la Caravana que viene en camino hacia Jalisco, ya fragmentada en el contingente que coordina "el Chele" y el que dirigen cuadros de Pueblo Sin Fronteras. Se plantea adónde van a llegar, qué protocolos se van a seguir e insisten, pese a la experiencia anterior, que el Auditorio Benito Juárez será el adecuado y que realizaran una campaña de sensibilización entre los vecinos para que acepten la situación.

14 Esta Secretaría pretende recoger todas las problemáticas sociales de mujeres, pueblos indígenas, migrantes, diversidad sexual... Al hacerlo finiquita el Instituto de las Mujeres y, también, el Instituto Jalisciense de Migración. No funcionará. Actualmente la migración, los pueblos indígenas, los discapacitados, la diversidad sexual y los menores han pasado a ser parte de una subsecretaría de Derechos Humanos dentro de la Secretaría General de Gobernación, mientras las políticas de género se concentran en la Secretaría de Igualdad Sustantiva entre Hombres y Mujeres. 
Parecería que se iba a continuar y replicar el comportamiento de recibida y de operativo de atención integral y organización que se dio en el Auditorio Benito Juárez en noviembre, y que el gobernador protagonizaría esta atención. Pero no fue así. Por un lado, el Auditorio estaba ocupado con otras actividades y por otro parecen caer en cuenta que no conviene desgastarse públicamente, ya que sienten que la población no está conforme con el gasto de los recursos en los integrantes de la Caravana. Hay un cambio de actitud, de discurso, de operación. Al gobernador no parece interesarle verse vinculado al paso de la Caravana, ni para bien, ni para mal.

Entonces se le solicita a El Refugio Casa del Migrante y del Refugiado que se abra a recibir la caravana en curso, y las instancias del gobierno ofrecen su completo apoyo. Al mismo tiempo afirman que van a mantenerse, por decisión propia, en un perfil bajo.

El grupo de El Chele arriba al albergue el 18 de febrero en la tarde noche, se conformaba por 326 integrantes -entre ellos más de 50 niños- que contaban con visas humanitarias. Su liderazgo se ha dado desde la salida de Honduras, y en la ciudad de México adelanta su contingente y se suman a su llamado entre 400 y 500 personas para partir a Mexicali, en el camino se desgajan del grupo los inconformes ${ }^{15}$. Si el paso de las Caravanas por el sur del país había sido más o menos fluido, al entrar ésta de El Chele al centro de México comienzan los tropiezos. En Querétaro no les ponen camiones y no se les permite tomar aventón ni de policías federales, ni de tráileres. Esta actitud obstaculizadora ya se estaba dando también en el sur del país. Arriban a Jalisco caminando y son sus municipios los que se hacen cargo de movilizarles hacia Guadalajara (los alcaldes se quejarán de la falta de apoyo y coordinación de parte del gobierno estatal). Llegarán a Zapotlanejo y, de allí, su municipalidad los dirige a El Cerro del 4.

Y el albergue colapsa. Las ayudas que se recibían de la población descienden, como desciende la información de esta Caravana en los medios de comunicación y, sobre todo, la ayuda prometida por el gobierno no llega como debiera. Pero también se dio en todo momento un amplio y diverso ${ }^{15}$ José Luis el Chele, el líder -presuntamente autónomo- que organiza el fragmento de Caravana que avanza sobre el resto desde el albergue de Ciudad Deportiva de Magdalena Mixhuca en la Ciudad de México, es salvadoreño y tiene 26 años. Aunque decía no conocer la ruta, parece que se coordinaba con el celular con gente del INM que le iban identificando los albergues, los buses y el apoyo de los municipios. En el trayecto, y aun en Mexicali, se sirvió del apoyo de las redes de las iglesias evangélicas. 
servicio de voluntarios que trabajó intensamente con el reparto de comida, de ropa y útiles, así como también en las labores de limpieza.

El día 20 de febrero la Caravana inicia su partida en buses financiados por diversas instancias católicas y públicas. La ayuda del gobierno sigue sin hacerse presente.

La salida se va a atrasar y se les transporta a La Venta del Astillero, a donde El Chele quería llegar, con lo que los integrantes tienen que caminar hasta la Caseta del Arenal. Se hace tarde y allí quedan estancados mujeres, niños y jóvenes... sin comida, sin ambulancias, sin acompañamiento, a pesar las denuncias de la sociedad civil. Solo está presente la Policía Federal y Protección Civil Nacional. Posteriormente justificarían esta falta de atención por presupuesto insuficiente. Asimismo, en las reuniones que mantienen se hacen ver los incumplimientos a Juan Carlos Martín Mancilla, del Sistema DIF e Igualdad Sustantiva, ellos argumentan la falta de comunicación, aunque se habían enviado los requerimientos a diferentes correos sin recibir respuesta ${ }^{16}$.

En una rueda de prensa del día 22, El Refugio Casa del Migrante y Refugiado entrega un comunicado y anuncia que no recibirá futuras Caravanas:

debido a la falta de apoyo y compromiso por parte de las autoridades correspondientes que no cumplieron con los acuerdos para la recepción y estadía de la Caravana. La decisión surge ante la necesidad de atender a los y las migrantes dignamente, trato que no se les pudo brindar en su totalidad por la falta de insumos y mobiliario para su estadía (El Refugio Casa del Migrante y el Refugiado)

El Refugio, que tiene una capacidad de 120 personas, continuará con las actividades normales de asistencia a personas migrantes en su tránsito por Guadalajara. De hecho en los meses siguientes seguirán llegando grupos numerosos, de unas 30 a 60 personas, que fluyen de forma continuada. Esta declaración supuso un fuerte posicionamiento de parte de una casa de migrantes por la inacción y omisión de las autoridades ante una problemática grave que prefieren minimizar.

\footnotetext{
${ }^{16}$ Se trajeron mesas, sillas y toldos, una vieja cocina móvil, mantas roídas que eran restos de la contingencia pasada en el Auditorio, se prometieron 8 bańos y se instalaron 4, uno sin funcionar. No se trajo comida ni agua, tampoco las prometidas duchas portátiles, que urgían.
} 


\section{El arribo de la segunda Caravana de febrero}

Ante este operativo fallido por parte del gobierno, su abandono al albergue y a la población migrante prácticamente despreciada, y ante la inminencia del arribo de un contingente bastante más numeroso, las estrategias del gobierno se modifican.

Este contingente, con una coordinación más institucional de Pueblo Sin Fronteras, está formado por unas 1,500 personas. Viene acompañado por el Instituto Nacional de Migración y por Protección Civil Federal. Ante las críticas recibidas por sectores civiles y religiosos como El Refugio o la CEDHJ, el gobierno de Alfaro opta por dejarlos fuera de la jugada y hasta de la observación. Por esta actitud poco comunicativa, el gobierno del Estado recibe una medida cautelar de parte de la segunda institución.

Su llegada se produce el sábado 23 de febrero. Sorpresivamente, sin avisar a las diferentes instancias de sociedad civil, se abren las instalaciones del Parque Solidaridad, en Tonalá ${ }^{17}$. Otra vez son los municipios los que facilitan la llegada a este punto. La organización parece que es óptima, aunque no hay ningún informe conocido que lo registre, se les ofreció buena comida, las instalaciones fueron suficientes y con separaciones por grupos, tenían canchas de futbol y bastante espacio, con lo que los caravaneros no buscaron salir de su perímetro. Pasan dos noches y finalmente los sacan en camión hasta la Caseta del Arenal. Otra vez quedan allí abandonados y serán integrantes de la Congregación de Cristo Resucitado quienes, en la noche que pasan allí las personas migrantes a la intemperie, les llevan ollas de comida ${ }^{18}$. De nuevo será tortuoso su avance hacia la frontera norte.

Pocos días después, parte del equipo de la Secretaría de Igualdad Sustantiva, que coordinó el operativo de atención en el Parque, convoca a una reunión para hacer un análisis de la situación de las Caravanas. Comunican las dificultades que han enfrentado para dar la ayuda humanitaria, tanto en términos presupuestales, como de respaldo por parte de otros funcionarios y

\footnotetext{
${ }^{17}$ El Parque Solidaridad, en Tonalá, al oriente de sectores populares del área metropolitana, es un amplio espacio de 110 hc. dedicadas a la recreación.

${ }^{18}$ Esta congregación de misioneros y misioneras tiene su sede en Guadalajara. Desde el inicio del proceso de las Caravanas estuvieron presentes en el acompańamiento de las mismas con una clínica móvil. La hermana Bertha López Chávez es parte de los defensores de derechos de los migrantes criminalizados por su trabajo.
} 
de una parte de la sociedad, y queda manifiesta su escasa preparación para este tipo de contingencia.

\section{Puntos de reflexión}

En esta segunda sección se hace una revisión de algunos aspectos teóricos que pueden ayudar a una mejor comprensión de los hechos expuestos. Primero se hace un balance acerca de la gestión de las caravanas en Jalisco; después nos centramos en lo que hemos denominado comportamiento "desconcertante" de las personas migrantes; finalmente nos referimos a los eventos de agencia migrante.

\section{La gestión de las caravanas en Jalisco}

Los gobiernos de los diferentes niveles de México se vieron retados con las Caravanas y probaron distintas medidas, desde el apoyo y la negación de la ayuda, la contención y los aseguramientos, al laissez faire, laissez passer, y hasta el paso libre. De parte de los gobiernos de Jalisco nos parece que han realizado una gestión inconsistente, caótica e irregular, donde prevalece el evitar la implicación.

Los gobiernos, en octubre y febrero, quisieron obtener protagonismo con la Caravana, pero fueron instantes que no se mantuvieron. Aprovechando que el estado se encuentra en el camino al norte, prefieren salir del problema y la opción fue la fuga hacia adelante, en octubre con la expulsión de los migrantes del Auditorio y, después, con el bajo perfil del gobierno de Movimiento Ciudadano. Estos son los cálculos políticos que van realizando las autoridades en función de múltiples variables, los migrantes en grandes oleadas suponen gastos y desgaste político por la reacción de la ciudadanía ante la ayuda humanitaria que se brinda a las personas migrantes y refugiadas, y saben que lo que desean los desplazados es alcanzar la frontera norte.

Se podría entender que aplican una política de higienización social, es decir, de hacer pasar de la forma más desapercibida posible a los expulsados por insostenibilidad de la vida, para que no "contaminen" la ciudad". Aunque como hemos visto, en Guadalajara no lo van a hacer con buen tino, primero los introducen al centro, buscando tenerles encerrados y provocando conflictos

\footnotetext{
${ }^{19}$ La higienización social supone una "limpieza social” por parte de la administración pública, para Lefebvre es parte de medidas políticas y culturales de homogenización y control del espacio urbano (2013).
} 
Camus Bergareche

Vega Villaseñor

Martínez Hernández
Tensiones en la gestión de las caravanas migrantes...

con ello; y después, al área metropolitana, buscando que la Caravana pase desapercibida. La urgencia por sacarlos de la ciudad se suma a su falta de responsabilidad por no completar su compromiso de llevarlos de forma segura a los límites con Nayarit, abandonando a los caravaneros en lugares inhóspitos y desprotegidos como la Caseta del Arenal, en el sol y la intemperie, sin comida, agua ni techo (CNDH, 2018: 6).

Por otro lado, los funcionarios no saben, o no quieren, contar con la sociedad civil, quizás desconfían de sus integrantes. Pero la utilizan y, cuando la requieren, incumplen su trato. Hasta ahora han sido los albergues los encargados de la atención a los migrantes, con el apoyo de toda una constelación de instancias religiosas y civiles, y también de bienhechores, donantes y voluntarios. El gobierno y los estados les han delegado la acción humanitaria y el acompanamiento -también el jurídico- en un outsourcing informal y desigual. En la primera Caravana, el gobierno contó con el FM4 en un primer momento, luego desairó a la institución sin mayores explicaciones. En la segunda oleada, la estafeta se delegó al albergue de El Refugio, al que se dejó sin la ayuda prometida y luego se le desconoció. Otras instancias con un largo y profesionalizado trabajo con los migrantes tampoco fueron consideradas y tuvieron que ejecutar un papel de acompańamiento de urgencia, por el abandono de los dos gobiernos, en los dos momentos más álgidos de exposición y vulnerabilización de las personas migrantes aventadas en la caseta de la autopista.

Es difícil establecer una valoración de la postura que tiene la sociedad en Guadalajara en este sentido, ya que se han manifestado con fuerza acciones solidarias y discursos de rechazo. Lo que sí puede decirse es que el apoyo en donativos y voluntarios no se ha podido mantener en el mismo nivel a lo largo del paso de las Caravanas. Lo mismo ha sucedido con la cobertura mediática, el tema perdió novedad.

Los migrantes centroamericanos irregulares han tendido a regresar a modalidades anteriores, como tomar el tren y volver a los albergues en volúmenes más atendibles, pero con un ritmo continuo que ha sido extenuante para los equipos de asistencia. En estos meses de movimiento épico de migrantes, la coordinación, información, solidaridad poblacional y la calidad de atención han descendido; mientras que los obstáculos de parte de las diferentes instancias de gobierno se han acentuado, a pesar de un discurso 
más amable a favor de la regularización de los flujos desde el supuesto respeto a los derechos humanos ${ }^{20}$. Con el despliegue de la Guardia Nacional en el sur del país y la progresiva conversión de México en tercer país seguro, las dinámicas cambian y, de nuevo, el papel de las casas e instancias de apoyo a migrantes desafían la reflexión y acción ético-política y académica.

\section{El comportamiento "desconcertante" de los migrantes}

Algo que llama la atención en las operaciones de los gobiernos estatales hacia las Caravanas es el desconocimiento sobre los sujetos migrantes (CEDHJ, 2018; COLEF, 2019B). En Guadalajara también se pudo observar, especialmente en el tratamiento de las tensiones que se dieron en el Auditorio Benito Juárez. A los diferentes funcionarios y a la población en general les cuesta entender las condiciones del colectivo desplazado. El comportamiento inesperado de los migrantes centroamericanos clandestinos por México es algo sabido en las organizaciones que los atienden. Desde estos espacios se observan sus inconsistencias e inconstancias, pero asumen una comunicación limitada y compleja porque trabajan con ellos y los aceptan con su problemática y su riqueza.

Los espacios de vida y experiencias de donde proceden los sujetos desplazados están marcados por la violencia extrema, tanto en sus manifestaciones visibles y explícitas, como en las invisibles violencias estructurales, simbólicas o naturalizadas (Bourgois, 2009) y, como señalamos, tienen además una proyección histórica en su despojo. Una vez en el tránsito, una importante fuente de violencia son las políticas migratorias que los ilegalizan y absorben su problemática desde las lógicas de la seguridad nacional (París Pombo, 2017). Las convenciones de soberanía y seguridad nacional se han hecho incuestionables y establecen quiénes pueden o no pueden traspasar el territorio de las naciones según el interés que tengan para el sistema de producción. Las políticas migratorias definen "legalmente" este filtro, ejecutando una política que es racista y es clasista. Los desplazados centroamericanos (y otros) que logran pasar las fronteras prohibidas quedan desposeídos de derechos y los vemos convertidos en el chivo expiatorio de regímenes crudos de deportación y exclusión por raza, clase, nacionalidad o religión (De Genova y Peutz, 2010).

\footnotetext{
${ }^{20}$ Ariadna Estévez señala cómo el discurso de los derechos humanos puede ser una herramienta de lucha y resistencia y, al mismo tiempo, disfraza y es parte activa de la administración políticamente correcta del sufrimiento de las víctimas del capitalismo neoliberal (2017).
} 
Los procesos de constante vulnerabilización que sufren las personas migrantes en el tránsito por México generan un desajuste del habitus (Bourdieu, $2000)^{21}$. Es lo que en otros trabajos se ha denominado como "habitus migrante", que en el contexto del tránsito "supone poner en práctica todas las estrategias posibles para poder obtener los recursos necesarios que permitan el logro deseado: llegar a los Estados Unidos" (Vega, 2018B:72). Esto supone que en diferentes situaciones las personas migrantes asumen comportamientos que en otro contexto tendrían una calificación moral negativa (engańar, mentir, hacer trampa, inventar historias, robar, acaparar, despertar lástima, querer ser el primero en recibir ayuda, etc.). Se trata de "esquemas clasificatorios, principios de clasificación, principios de visión y división, de gustos diferentes" (Bourdieu, 1997:34) que han sido desajustados violentamente y reestructuran, "al menos provisional y emergentemente, a la persona toda" (Vega, 2018A: 165); desde una perspectiva socio-antropológica, es lo que estaría en la base de lo que llamamos comportamientos "desconcertantes" de los migrantes.

$\mathrm{Al}$ entender a los integrantes de las Caravanas dentro del dilema clásico en las ciencias sociales entre la victimización por la fuerza de la opresión y sus efectos destructivos, y la capacidad de agencia, resistencia y decisión de los sujetos, nos quedamos en un terreno intermedio. En la etnografía sobre las brutalidades institucionalizadas en un barrio del nordeste brasileño donde los niños mueren de hambre, de Nancy Scheper-Hugues (1997), se rescatan los talentos de estos pobladores y cómo, a pesar de sus sufrimientos, mantienen la creencia de su derecho a estar vivos. Aunque en los caravaneros su opción de fuga se restringe al estrecho margen que dejan los Estados, las políticas migratorias y el asedio de diversos grupos criminales y otros elementos obstaculizadores, salen adelante con astucia, saltándose las normas y aprovechándose de situaciones, personas e instituciones. "Lo suyo no es la resistencia, sino simplemente la existencia" (ibíd.: 509).

Además del espíritu optimista con que nos sorprenden estos centroamericanos expulsados, muestran un sentido de trascendencia religiosa, sean católicos o evangélicos-cristianos, de nuevo más allá de los límites de esa agencia, individual o colectiva, entendida como la capacidad

\footnotetext{
${ }^{21}$ El habitus son las disposiciones que tienen los agentes para actuar en el campo social, una estructura -estructurada y estructurante- "producto de condicionamientos sociales asociados a la condición correspondiente” (Bourdieu, 2000: 33); se va configurando a lo largo de la vida y se compone de distintos capitales: cultural, capital social, capital económico, capital religioso, etc.
} 
de tomar decisiones y de transformar. Tradicionalmente la religión ha sido considerada un factor de alienación y desempoderamiento, pero vemos la fuerza y certidumbre que les ofrece a los desplazados y cómo es también un recurso de sobrevivencia y de protección sobrenatural ante la precarización y los peligros, y un proceso simbólico de reconstrucción de memorias y de los derechos individuales y colectivos que les permite dar sentido a las experiencias vividas (FM4 paso libre, 2017).

\section{Eventos de agencia en los migrantes}

Las caravanas fueron un arranque organizativo colectivo que permite perfilar una cierta acción política con muchas contradicciones. Los sujetos que se suman a ellas se encuentran, como estamos viendo, inmersos en la precarización y el desplazamiento, y se mueven dentro de una lógica de sobrevivencia, absorbidos por el día a día y en estado de excepción (Agamben, 2010). El ejercicio de su opción de fuga (Mezzadra, 2005) como caravaneros se ve limitado al verse expuestos a tantas fuerzas que les presionan y agreden, insertos en habitus desajustados donde reciben violencias, pero donde también las ejercen y las producen.

Vemos que las Caravanas rompen con la "individualidad" -digamos apolítica- en que se ha manifestado el tránsito clandestino a Estados Unidos. Encontramos en ellas el funcionamiento de unas asambleas y unos líderes que ponen cierto orden, cierta dirección política y politizada, dentro de la vorágine. Hay un liderazgo intermitente en la coordinación de Pueblo Sin Fronteras, a quienes vimos funcionando como interlocutores directos con el gobierno, muchas veces haciendo de lado a sus posibles aliados locales que son los que dan el acompañamiento sistemático en otros momentos. Pero también tenemos un tipo de liderazgo que se produce desde los participantes de la Caravana de una manera más espontánea, quienes, por sus habilidades sociales, como señala también el COLEF (2018), lograron hacerse intermediarios válidos frente a los medios y a otras organizaciones, como lo era El Chele. Y podemos añadir de forma hipotética, dentro de este colectivo más informal, a 
quienes podrían haberse infiltrado desde el crimen, más o menos, organizado interesados en capitalizar los cuerpos migrantes ${ }^{22}$.

Estas presencias con autoridad quedaban más difusas en el acontecer cotidiano de sus integrantes. En entrevistas realizadas a miembros de la Caravana en el albergue de El Refugio, estos comentan que los líderes de Pueblo Sin Fronteras no estaban presentes en largos momentos porque "ellos iban hasta adelante y nosotros éramos los últimos" (Flor) ${ }^{23}$. Los integrantes de las Caravanas cuentan cómo entre ellos se formaban "grupitos" para acompañarse, dice Gina, para "refugiarse", y se daban acciones solidarias, aunque también se daban tensiones entre nacionalidades. La familia de Flor, compuesta por seis personas que salían de El Salvador por amenazas, creyó que iba a encontrarse con la Caravana de salvadoreños, pero dieron con la de hondureños y tuvieron que ocultar su procedencia si no querían verse maltratados. Las mujeres se quejan: "cuando decían 'mujeres y niños primero', parecía que dijeron 'súbanse todos los varones'. No respetaban nada, nada. Y decían que inflaba mi panza -estaba embarazada- para que él [su esposo] subiera, que él no venía conmigo" (Flor) (ver CEDHJ, 2018) ${ }^{24}$. Los niños de 2-3 años no se querían levantar en las madrugadas, tenían frío, se enfermaban, estaban cansados y se resistían a seguir. Las madres llevaban muchas maletas y "los varones querían salir rápido y se desesperaban. Desde las dos ya estaban 'vámonos, ya es hora”" (Flor).

Gina señala lo mismo sobre la urgencia juvenil y aún le atormenta lo que vio sufrir a los niños, tiene "su llanto en los oídos". Los bańos eran otro problema, "cuatro o cinco para mil. No había privacidad para bañarse, nosotras [éramos] más aseadas y los manteníamos bien, pero cuando los varones ya todo sucio lo dejaban... entraban donde las hembras. Ellos no lo miran” (Flor). Además muchos no se preocupaban por la basura y "exigían demasiado, ven como

\footnotetext{
22 Para el COLEF (2018), la Caravana es una forma masiva y protegida de recorrer México y supone un grado de organización más alto que en la migración "por goteo", de carácter individual o en grupos pequeños. Se distinguen varios tipos de liderazgos, según el momento en que surgen y la escala que alcanzan, aunque todos estos protagonismos se producen de manera simultánea y superpuesta, también llegan a contraponerse y a entrar en tensión y en conflicto.

${ }^{23}$ Los testimonios proceden de entrevistas y conversaciones hechas en diferentes momentos en el albergue de El Refugio con personas que venían o que se fueron -y volvieron- en las Caravanas.

${ }^{24}$ En este sentido prevaleció, pese a unos flujos de composición novedosa en términos de género y etarios, un escenario patriarcal que mantiene su hegemonía.
} 
Camus Bergareche

Vega Villaseñor

Martínez Hernández
Tensiones en la gestión de las caravanas migrantes...

obligación que les estuvieran dando" (Gina). En estos testimonios tenemos sectores como las mujeres, los niños y los menores no acompañados que se ven como abandonados a su suerte dada la insuficiencia de la capacidad organizativa de los líderes.

El ambiente de un cotidiano de sobrevivencia y competencia lo sufre también Sandra, hondureña de 26 años. Ella se suma a la Caravana que sale del Parque Solidaridad, en Guadalajara (había llegado meses antes), porque conocía a una persona que era de la organización, pero las mujeres integrantes la maltrataron desde el inicio por no estar en las listas y el líder no la defendió, la dejaban sin comer y no podía entrar a las carpas, la robaron su maleta y su dinero... Un día la golpearon y decidió subirse al tren con unos muchachos. Así llegó a Mexicali.

Otro tipo de condicionamientos en la capacidad de acción lo exponen los investigadores del COLEF cuando preguntan a los caravaneros: “ipor qué llegaron a Piedras Negras?”, para concluir que "las respuestas muestran un bajo consenso en la definición del destino fronterizo, a la vez que se percibe cierta aleatoriedad al tomar esa decisión según se presenten las circunstancias (dejarse llevar por la Caravana o porque se les apoya con transporte a un punto no definido por quienes viajan)" (2019B: 35). También lo rescatan cuando se produce un proceso de desintegración y se forman subgrupos que se dirigen a diferentes ciudades: Reynosa, Matamoros, Monterrey, porque pensaban que en otros lugares sería más fácil pedir asilo a Estados Unidos, entonces la acción institucional fue ponerles buses para su traslado buscando deshacerse de las personas migrantes. Es la "fragmentación del grupo a razón de políticas o acciones institucionales en ambos lados de la frontera, así como a decisiones personales y colectivas entre los integrantes de la Caravana" (COLEF, 2019B: 68).

Hay esfuerzos y logros importantes en la promoción de la conciencia política y organizativa de los sujetos migrantes, por ejemplo, de parte del Movimiento Migrante Mesoamericano ${ }^{25}$, pero los condicionamientos para una acción libre y contrahegemónica son evidentes por lo expresado

${ }^{25}$ El Movimiento Migrante Mesoamericano trabaja por los derechos de los migrantes mexicanos y centroamericanos en tránsito por México de forma coordinada con organizaciones y con familiares de víctimas de desaparición en el tránsito (Varela, 2016). Surge en 2006 con el arribo como deportados a México de activistas por los derechos de los migrantes en Estados Unidos. Su demanda es "todos los derechos para todos". También ha apoyado el "Viacrucis migrante". 
Camus Bergareche Vega Villaseñor Martínez Hernández
Tensiones en la gestión de las caravanas migrantes...

anteriormente: su extrema precariedad y el habitus desajustado a que los han llevado las desposesiones históricas y las más actuales políticas neoliberales, así como las políticas migratorias igualmente desposeedoras de sus derechos y de su propia subjetividad. Ańadido a estas opresiones, encontramos un interés por negar e invisibilizar la voz migrante si no habla como víctima, como receptor pasivo de ayuda o como migrante económico.

En consonancia con lo anterior, siguiendo el pensamiento de Edgar Morin (1984), llamamos eventos de agencia a acciones singulares que realizan en muchos casos las personas migrantes o quienes tienen algún tipo de liderazgo. La evenencialidad remite a lo no programado, a aquello que acontece una sola vez, de manera inesperada, de forma particular y por lo tanto es difícil de generalizar.

Lo que observamos en la Zona Metropolitana de Guadalajara fueron eventos de agencia, ya sea de parte de algunos migrantes, de activistas que los acompañaban o de actores locales de la sociedad civil o del gobierno, que en algún momento o situación asumieron un liderazgo y tomaron decisiones que afectaron a los grupos sin una coordinación, sin objetivos ni estrategias definidos y acordados entre todos.

Así, los liderazgos observados en las caravanas se generan en una configuración coyuntural, no se dimensionan en un proyecto colectivo a largo plazo, no producen regularidades, no desembocan en las mejores decisiones, ni en el favorecer a todos. Sus acciones y propósitos tienen incertidumbre, orden y desorden, necesidad y azar, y también, en algunos momentos, llegan a conformar un tejido organizado que permite movilizar miles de desplazados.

El proceso del viaje de las Caravanas lo entendemos como una suma de distintos eventos que se conjugan y que facilitan una cierta organización y agencia, entonces se armonizan las diferencias, se conjuntan los deseos, y logran un objetivo que quizá no era el que pensaban todos, pero tiene un impacto más o menos favorable. Por ejemplo, con el hecho de caminar en caravana hicieron que el gobierno se replanteara sus políticas migratorias y, al mismo tiempo, atrajeron la atención de los medios y simpatía de la población. Sin embargo, su escasa consistencia organizativa facilitó su desarticulación con el tiempo. 
Con las Caravanas no podríamos hablar de una agencia migrante como tal, sino de eventos de agencia por parte de algunas personas o grupos migrantes en coyunturas particulares que las facilitan ${ }^{26}$. Y estos eventos se suman a otras agencias desde la sociedad civil, a grupos espontáneos e instancias gubernamentales. Sin embargo, esta confluencia protagonista de agencias desde los que reivindican y practican el derecho a migrar significó un cuestionamiento y, en cierta forma, develamiento de políticas migratorias en gran medida contradictorias entre los discursos y las prácticas, que oscilan del humanitarismo hacia los expulsados centroamericanos a su persecución y criminalización.

\footnotetext{
${ }^{26}$ No todos los integrantes de las Caravanas comparten las propuestas políticas y organizativas, se dan condiciones, experiencias, intereses, responsabilidades, competencias y capitales distintos (Bourdieu, 2000) y la agencia puede verse mediada por la necesidad, la coacción, las naturalizaciones de las violencias simbólicas.
} 
Camus Bergareche

Vega Villaseñor

Martínez Hernández
Tensiones en la gestión de las caravanas migrantes...

\section{Bibliografía}

Agamben, Giorgio, (2010) Homo sacer. II Estado de Excepción. Valencia: PreTextos.

Bourdieu, Pierre, (2000) Poder, derecho y clases sociales. Bilbao: Desclée de Bouwer.

Bourdieu, Pierre, (1997) Capital cultural, escuela y espacio social. México: Siglo XXI Editores.

Bourgois, Philippe, (2009) "Treinta años de retrospectiva etnográfica sobre la violencia en las Américas” en López García, Julián; Bastos, Santiago y Manuel Camus (editores), Guatemala: Violencias desbordadas. Córdoba: Universidad de Córdoba, pp 27-62.

Camus, Manuela, (2019) "Las movilidades de los centroamericanos por insostenibilidad de la vida" ponencia para el seminario Retornos, tránsitos, circularidades y asentamientos provisionales. Migrantes atrapados en las movilidades. Colegio de Michoacán, 24 octubre.

Cerna, Cecilia, (2018) "Hay que ser solidarios ante necesidad de migrantes: Aristóteles Sandoval" en El Occidental. Disponible en https://www. eloccidental.com.mx/local/hay-que-ser-solidarios-ante-necesidad-demigrantes-aristoteles-sandoval-2652411.html.

Comisión Estatal de Derechos Humanos Jalisco (CEDHJ), (2018) Informe Éxodo Centroamericano. Disponible: en: http://cedhj.org. $\mathrm{mx} /$ recomendaciones/inf.\%20especiales/2018/INFORME\%20 \%C3\%89XODO\%20CENTROAMERICANO.pdf [Recuperado 10 de julio de 2019].

Comisión Nacional de Derechos Humanos (CNDH), (2018) Informe Especial. Participación de la CNDH en la Audiencia Regional: Situación de derechos humanos de las personas que integran la Caravana de Migrantes ante la Comisión Interamericana de Derechos Humanos, 6 de diciembre de 2018. Disponible en: http://www.cndh.org.mx/sites/all/ doc/Informes/Especiales/inf-cndh-cidh-caravana.pdf [Recuperado el 18 de enero de 2019].

Composto, Claudia y Mina Lorena Navarro, (2014) "Claves de lectura para comprender el despojo y las luchas por los bienes comunes naturales en América Latina", en Composto y Navarro (compiladoras), Territorios en disputa. Despojo capitalista, luchas en defensa de los bienes comunes 
naturales y alternativas emancipatorias para América Latina. México, D. F.: Bajo tierra ediciones.

De Genova, Nicholas y Peutz, N., (2010) The Deportation Regime: Sovereignty, Space, and the Freedom of Movement. Durham, NC.: Duke University Press.

El Colegio de la Frontera Norte (COLEF), (2018) La caravana de migrantes centroamericanos en Tijuana, 2018. Diagnóstico y propuestas de acción. Disponible en: https://www.colef.mx/estudiosdeelcolef/la-caravanade-migrantes-centroamericanos-en-tijuana-2018-diagnostico-ypropuestas-de-accion/.

El Colegio de la Frontera Norte (COLEF), (2019A) La caravana de migrantes centroamericanos en Tijuana, 2018-2019 (Segunda etapa). Disponible en: https://www.colef.mx/wp-content/ uploads/2019/03/2o.-Reporte-Caravana-Tijuana.250319.pdf.

El Colegio de la Frontera Norte (COLEF), (2019B) La Caravana centroamericana de migrantes en Piedras Negras, Cohauila 2019. Diagnóstico y propuestas de acción. Disponible en: https://www.colef. $\mathrm{mx} /$ estudiosdeelcolef/la-caravana-centroamericana-de-migrantes-enpiedras-negras-coahuila-2019-diagnostico-y-propuestas-de-accion/.

Estévez, Ariadna, (2017) "La repolitización de los derechos humanos frente a la gubernamentalidad neoliberal del sufrimiento social: una lucha de contraconducta” en Estévez y Vásquez (coor.) 9 razones para (des) confiar de las luchas por los derechos humanos. México: UNAM y FLACSO.

FM4 Paso Libre, (2017) "Sin lugar en el mundo. Desplazamiento forzado de mujeres por Guadalajara" en Informe-Investigación de FM4 Paso Libre. Guadalajara: Editorial Prometeo.

FM4 Paso Libre, (2018) Actualización sobre la Caravana Migrante. [Facebook] 13 de noviembre de 2018. Disponible en: https:// es-la.facebook.com/FM4PasoLibre/photos/actualizaciónsobre-la-caravana-migrantecompartimos-con-ustedes-estecomunicado-/10157022383499752/[Recuperado el 10 de julio de 2019).

Lefevbre, Henri, (2013) La producción del espacio. Madrid, España: Capitán Swing. 
Camus Bergareche

Vega Villaseñor

Martínez Hernández
Tensiones en la gestión de las caravanas migrantes...

Mezzadra, Sandro, (2005) Derecho de fuga. Migraciones, ciudadania y globalización. Madrid: Traficantes de sueños.

Morin, Edgar, (1984) Ciencia con consciencia. Barcelona: Anthropos, Editorial del Hombre.

París, Dolores, (2017) Violencias y migraciones centroamericanas en México. México: COLEF.

Pueblo Sin Fronteras, (2018) Éxodo Centroamericano "Comunicado". Dispónible en: https://www.facebook.com/PuebloSF/photos/a.2673 91253287583/2450456291647724/?type=3\&theater [Recuperado el 10 de julio de 2019].

Scheper-Hugues, Nancy, (1997) La muerte sin llanto. Violencia y vida cotidiana en Brasil. Barcelona: Ariel.

Varela, Amarela, (2016) "Luchas migrantes en contextos de tránsito migratorio. El caso del Movimiento Migrante Centroamericano" en Revista Interdisciplinaria de Mobilidad Humana. REMHU, n 48, pp 31-44.

Vega, Heriberto, (2018A) Migración de tránsito y acción humanitaria. Guadalajara: Editorial Universitaria-Universidad de Guadalajara.

Vega, Heriberto, (2018B) "Pastoral de migrantes como acción humanitaria" en Cuadernos Fe y Cultura, 36. México: Sistema Universitario Jesuita/ Fideicomiso Fernando Bustos Barrena.

\section{Entrevistas}

Flor, salvadoreña. Realizada en El Refugio, Casa del Migrante. 23/1/2019.

Gina, guatemalteca. Realizada en El Refugio, Casa del Migrante. 6/3/2019. 